\title{
The impact of innovative and emerging technologies on the surveying activities
}

\author{
Francesco Mancini ${ }^{1} \cdot$ Marco Piras $^{2} \cdot$ Laura Ruotsalainen $^{3} \cdot$ Giuseppina Vacca $^{4} \cdot$ Andrea Lingua $^{2}$
}

Published online: 14 March 2020

(C) Società Italiana di Fotogrammetria e Topografia (SIFET) 2020

\begin{abstract}
Surveying activities benefit from the continuous and rapid evolution of sensors, methodologies, and processing strategies. Such rapid development influenced the pre-existing geomatics applications in many fields and opened the way to more productive and accurate applications of surveying methodologies. This special issue aims at collecting papers focused on current and/or forthcoming sensors, novel applications and improvements in the surveying practices, and algorithms oriented to the handling of the increasing amount of data produced by automated procedures. Of particular interest is assessing the reliability, performance, precision, and limits for advanced applications in the field of photogrammetry, remote sensing, surveying, and mapping employed in innovative approaches to geomatics. These topics were discussed during the 68th meeting of the Italian Society of Photogrammetry and Survey (SIFET) held in Gaeta, Italy on 2022 June 2018, and the present special issue includes a number of papers presented during that event.
\end{abstract}

Francesco Mancini

francesco.mancini@unimore.it

Marco Piras

marco.piras@polito.it

Laura Ruotsalainen

laura.ruotsalainen@helsinki.fi

Giuseppina Vacca

vaccag@unica.it

Andrea Lingua

andrea.lingua@polito.it

1 Department of Engineering 'Enzo Ferrari', Università degli Studi di Modena e Reggio Emilia, Modena, Italy

2 Department of Environmental, Land and Infrastructure Engineering, Politecnico di Torino, Torino, Italy

3 Department of Computer Science, University of Helsinki, Helsinki, Finland

4 Department of Civil and Environmental Engineering and Architecture, University of Cagliari, Cagliari, Italy
In particular is the inclusion of papers on modern approaches in photogrammetry and research activities ranging from underwater to aerial surveying by means of handheld visible light cameras and multispectral sensors mounted onboard unmanned aerial vehicle (UAV). Such applications face a range of issues related to environmental and cultural heritage research. In these fields, the authors demonstrate the extreme flexibility and productivity of novel technologies based on photogrammetry and computer vision for timely investigation of natural resources and built environments using low-cost non-metric cameras with successive highly automated processing strategy. Issues related to multi-temporal comparison of point clouds and three-dimensional models are also addressed after the reconstruction of features at very high spatial and temporal resolutions. Moreover, in this special issue, the reader can find applications related to the combined use of novel approaches in close-range photogrammetry and terrestrial laser scanning for mutual quality enhancement. Other topics refer to the most recent solutions in global navigation satellite systems (GNSS) positioning in light of the modernization of constellations and development of low-cost sensors with considerable performance improvement to final positioning. The revision process selected seven papers strongly focused on these topics.

Rossi et al. (2019) presented a paper on a multi-temporal underwater photogrammetric survey of a reef patch located in Moorea, French Polynesia, designed to detect an expected coral growth of $10-15 \mathrm{~mm} /$ year for a patch with a particular structural complexity and ecologically relevant characteristics. In this paper, the authors used a reference network to provide a common frame for multi-temporal comparisons of 3D models, achieving an accuracy on the order of $1 \mathrm{~cm}$ in the estimation of coral growth. Taddia et al. (2019) presented an application of UAV photogrammetry oriented to monitoring submerged seaweed in shallow water using a multispectral lightweight camera designed for drones. The authors demonstrated the usefulness of such a tool in the monitoring of algal blooms, provided that a proper radiometric correction is 
applied to the acquired data. Issues related to the validation process of 3D multisource/multiresolution models was also faced by Tucci et al. (2019) for railway infrastructures where the requirement of reliable spatial data infrastructures is well described in addition to issues related to compliance with existing standards. Innovative 3D survey techniques were also introduced by Bertellini et al. (2019) as used for the conservation and enhancement of an example of Venetian historical architecture. In this paper, the authors combined laser scanning and photogrammetric surveys to investigate detailed geometric properties of the ceiling of the Sala Capitolare (Scuola Grande di San Rocco, Venice, Italy). Developments in precise point positioning (PPP) by GNSS were introduced by Dabove et al. (2019) using data from a multi-constellation under the condition of phase scintillation at high latitudes. In this regard, the authors discussed the benefits of using a higher number of satellites in the coordinate estimation for a continuous GNSS reference station located in Antarctica. In a similar application, Poluzzi et al. (2019) discussed the performance of low-cost GNSS receivers for monitoring purposes, providing the evidence that many of the monitoring tasks could also be performed using such a class of receivers while the real-time solutions could be designed for early warning purposes. Finally, the paper by Bellone et al. (2020) used a blend of geomatics and linguistics techniques in the reconstruction of a map on the basis of a written text representing a pictorial description of a panoramic mountain view.
The editors hope that the scientific community interested in the use of modern and emerging technologies in the field of surveying and geomatics will find the papers published in this special issue useful for their upcoming investigations.

\section{References}

Bellone T, Dante V, Mandelli A, Mussio L (2020) An example of syntactic and semantic ties among images, texts and maps. Appl Geomat. https://doi.org/10.1007/s12518-019-00294-3

Bertellini B, Gottardi C, Vernier P (2019) 3D survey techniques for the conservation and the enhancement of a Venetian historical architecture. Appl Geomat. https://doi.org/10.1007/s12518-019-00267-6

Dabove P, Linty N, Dovis F (2019) Analysis of multi-constellation GNSS PPP solutions under phase scintillations at high latitudes. Appl Geomat. https://doi.org/10.1007/s12518-019-00269-4

Poluzzi L, Tavasci L, Corsini F, Barbarella M, Gandolfi S (2019) Low-cost GNSS sensors for monitoring applications. Appl Geomat. https://doi.org/10.1007/s12518-019-00268-5

Rossi P, Castagnetti C, Capra A, Brooks AJ, Mancini F (2019) Detecting change in coral reef $3 \mathrm{D}$ structure using underwater photogrammetry: critical issues and performance metrics. Appl Geomat. https://doi. org/10.1007/s12518-019-00263-w

Taddia Y, Russo P, Lovo S, Pellegrinelli A (2019) Multispectral UAV monitoring of submerged seaweed in shallow water. Appl Geomat. https://doi.org/10.1007/s12518-019-00270-x

Tucci G, Corongiu M, Flamigni F, Comparini A, Panighini F, Parisi EI, Arcidiaco L (2019) The validation process of a 3D multisource/multiresolution model for railway infrastructures. Appl Geomat. https://doi.org/10.1007/s12518-019-00286-3 